\title{
BOOK REVIEWS AND NEWS
}

\author{
Recensioni e Rassegna Bibliografica / Analyses de Livres et \\ Revue Bibliographique / Buchbesprechungen und Literaturschau
}

\section{ATLAS DES MALADIES CHROMOSOMIQUES}

AtLas of Chromosomal diseases. By J. de Grouchy and C. Turleau (Paris, France). Expansion Scientifique Française, Paris 1977 . Hard cover, $21 \times 27 \mathrm{~cm}$, 356 pp, 525 illustrations. Price: F 262.

The atlas that Jean de Grouchy and Catherine Turleau have just published is both precious and timely. Modern medicine has in fact been concerned with the problems of genetics through the chromosomal approach with such a confidence and impetus that neither Mendelian nor molecular genetics could have thus far obtained.

Therefore, it is not only those genetic schools that are already at work along the same direction, but, much more generally, medicine as a whole, that should be thankful for a fundamental reference book needed by researchers, clinicians, and general practitioners alike.

The about thirty chromosomal abnormality syndromes that have so far been identified are described from the genotypic, phenotypic, historic, and bibliographic viewpoints. The most original approach, however, is the initial one, where each chromosome is greatly enlarged and an updated indication of its genetic contents is given. Also of high value is the unbiased approach to certain ethical problems of cytogenetics as, e.g., in the case of the $47, \mathrm{XYY}$ syndrome for which the finding of a $20 \%$ frequency in subjects taller than $200 \mathrm{~cm}$ may alone disprove previous deterministic inferences.

Luigi Gedda

The Mendel Institute, Rome, Italy

\section{HUMAN BEHAVIOR GENETICS}

Compiled and edited by A.R. Kaplan (Cleveland, $\mathrm{OH}$, USA). Charles C. Thomas Publisher, Springfield, IL, 1976. Hard cover with jacket, $18 \times 25.5$ cm, XV + 479 pp, illustrated. Glossary, Reference author index, and Subject index. Price not indicated.

This is the first book to deal extensively and comprehensively with the comparatively new discipline of human behavior genetics and it does so in such a way that it may serve both as an introductory textbook for students and as a reference tool for researchers. This multiauthored approach consists of a few introductory chapters and of a series of reviews on the genetic aspects of intelligence, personality development, and conditions such as neurosis, homosexuality, schizophrenia. A number of chapters are also devoted to the study of association of behavior with biochemical and other biological variables. This book is beautifully designed and produced.

MECHANISMS IN TRANSMISSION OF SIGNALS FOR CONSCIOUS BEHAVIOUR

Edited by T. Desiraju (New Delhi and Bangalore, India). Elsevier Scientific Publishing Company, Amsterdam-Oxford-New York 1976. Hard cover, $17 \times 25 \mathrm{~cm}, \quad$ XII $+376 \mathrm{pp}$, illustrated. Subject index. Price: Dfl 120 / US \$ 46.25.

The carefully edited and beautifully produced proceedings of a symposium on brain research essentially dealing with the general principles of neural communication, neural organization for survival, programming of motor apparatus, and brain mechanisms underlying plasticity of behavior.

\section{CHROMOSOMES IN MITOSIS AND INTERPHASE}

By H.G. Schwarzacher (Vienna, Austria). SpringerVerlag, Berlin-Heidelberg-New York 1976. Part 3 in Vol. 1, The Living Mass (Die lebendige Mass), of the Handbook of Human Microscopic Anatomy 